\title{
Perceptions and Attitudes of Parents Toward Vaccination of Children in Western Balkan Countries: Trust in the Function of Improving Public Health
}

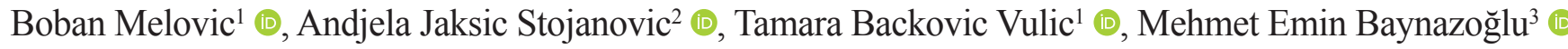

${ }^{1}$ Faculty of Economics, University of Montenegro, Podgorica, Montenegro

${ }^{2}$ Faculty of Economics, University of Donja Gorica, Podgorica, Montenegro

${ }^{3}$ Business Information Management, Trakya University, Edirne, Turkey

To the Editor,

Although vaccination is considered to be the most effective and cost-effective way of preventing the contraction of infectious disease, there are still many controversies about vaccines. Despite the trend of increasing vaccination rates worldwide, many factors may influence the formation of negative perceptions and attitudes, especially in developing countries, such as the Western Balkans. Studies have shown that the process of immunization, as one of the greatest public health achievements, is occasionally affected by strong social, cultural, and biological reactions from the public (1, 2 ). A significant number of countries are trying to develop motivational measures, whereas some of them are introducing the obligation of the vaccination process and penal policy in case of refusal. In that sense, understanding the attitudes and opinions of parents about the vaccination of children is essential for planning and undertaking extensive and properly directed educational actions to prevent their indecision and strengthen the trust in vaccines.

Considering all the aspects mentioned earlier, the authors performed the research to identify the factors that influence parents' perceptions and attitudes about children's vaccination, that is, trust in vaccines, and whether there is a significant difference in the analyzed countries. This is the first academic study that examines parents' perceptions and attitudes integrally across the 5 Western Balkan countries. The authors developed and empirically tested a model that examined the relationship between influential factors and parents' attitudes toward children's vaccination, that is, trust in vaccines. Online quantitative research was conducted in the first quarter of 2020 using the survey method. Multivariate factor analysis was applied to data collected from 2,193 parents in the analyzed countries. The relevance of the hypotheses was tested using standard statistical tests, analysis of variance, and eta coefficient.

The research showed that the analyzed variables from the model have a significant influence on parents' perceptions and attitudes about vaccination of children, which is reflected in the level of confidence in vaccines. Furthermore, the study showed that the attitudes and perceptions of the parents varied depending on the factor being observed. Thus, for example, social media is a relevant factor of influence on the formation of attitudes and perceptions of parents about the vaccination of children, which is why it is necessary to use this form of social marketing to improve public health.

The results of this research are correlated with other researches and studies (3) that showed that socioeconomic status, media information, attitudes, and motivations regarding healthcare and knowledge and awareness of the need for vaccines are related to the indecision about the process of vaccination. Furthermore, the important factors of influence are the age and education of the parents and the level of development of the country, which the authors wanted to investigate in this research. In this sense, the results of this segment of research correspond to similar researches in other countries. Thus, for example, some studies (4) have emphasized the age of parents, whereas others (5) have pointed out that decisions about vaccinating children largely depend on their level of education because a higher level of education is translated into a higher awareness or information being perceived differently, which was also confirmed in this study.

It is encouraging that the research showed that the largest number of respondents (parents), despite the strong influence of certain analyzed factors, have high confidence in vaccines. The results also showed that there is no statistically significant difference in the perceptions and attitudes of parents in the observed countries, which is not surprising at all considering that these are the countries with a similar level of economic development. The obtained results provide an important contribution to public health policymakers to identify and understand the impact of particular factors and, thus, to better adapt their initiatives to changes that will serve to improve public health.

Address for Correspondence: Mehmet Emin Baynazoğlu, Business Information Management, Trakya University, Edirne, Turkey

e-mail: meminbaynazoglu@trakya.edu.tr

Received: July 13, 2020 Accepted: July 29, 2020 •DOI: 10.4274/balkanmedj.galenos.2020.2020.7.110

Available at www.balkanmedicaljournal.org

ORCID iDs of the authors: B.M. 0000-0001-6330-9425; A.J.S. 0000-0002-4057-5939; T.B.V. 0000-0002-1421-6721; M.E.B. 0000-0003-1978-1348.

Cite this article as:

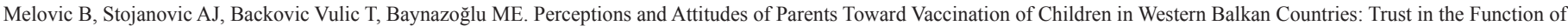
Improving Public Health. Balkan Med J 2021;38:59-60

Copyright@Author(s) - Available online at http://balkanmedicaljournal.org/ 
Ethics Committee Approval: The survey was organized in complete accordance with ethical standards. The research did not examine patients but only people's attitudes and perceptions about vaccination. The research did not involves human subjects, human material, human tissues, etc. In accordance with the above, the Ethics Committee informed us that no special permit is required for this type of research. This is an anonymous survey. It doesn't include of any personal information. Respondents voluntarily participated in the survey and all of them agreed to publish the results. All participants gave their informed consent for inclusion before they participated in the study. Hence, considering all previously mentioned, the Ethics Committee did not require any additional permission for conducting the research.

Patient consent for publication: All participants gave their informed consent for inclusion before they participated in the study.

Author contributions: Concept - B.M., A.J.S., T.B.V., M.E.B.; Design - B.M., A.J.S., T.B.V., M.E.B.; Supervision - B.M., M.E.B.; Resources - B.M., A.J.S.; Materials - B.M., A.J.S.; Data Collection and/or Processing - B.M., T.B.V., M.E.B.; Analysis and/or Interpretation - B.M., A.J.S., M.E.B.; Literature Search - B.M., A.J.S., M.E.B.; Writing - B.M., A.J.S., T.B.V., M.E.B.; Critical Review - B.M., A.J.S., T.B.V., M.E.B.
Conflict of Interest: The authors have no conflicts of interest to declare.

Funding: The authors declared that this study has received no financial support.

\section{REFERENCES}

1. MacDonald NE, Butler R, Dubé E. Addressing barriers to vaccine acceptance: An overview. Hum Vaccin Immunother 2018;14:218-24. [Crossref]

2. Betsch C, Brewer NT, Brocard P, Davies P, Gaissmaier W, Haase N, et al. Opportunities and challenges of Web 2.0 for vaccination decisions. Vaccine 2012;30:372733. [Crossref]

3. Larson HJ, Cooper LZ, Eskola J, Katz SL, Ratzan S. Addressing the vaccine confidence gap. Lancet 2011;378:526-35. [Crossref]

4. Brown K., Fraser G, Ramsay M, Shanley R, Cowley N, van Wijgerden J, et al. Attitudinal and demographic predictors of measles-mumps-rubella vaccine (MMR) uptake during the UK catch-up campaign 2008-09: Cross-sectional survey. PLoS One 2011;6:e19381. [Crossref]

5. Anderberg D, Chevalier A, Wadsworth J. Anatomy of a health scare: Education, income and the MMR controversy in the UK. J Health Econ 2011;30:515-30. [Crossref] 